\title{
Assessment of Knowledge and Practice of the Community towards Malaria and its Treatment in Jiren Kebele, Jimma Town Oromia, Ethiopia
}

\author{
Alemayehu Gutasa*, Desta Assefa, Kabaye Kumela \\ Department of Pharmacy, College of Public Health and Medical Sciences, Jimma University, Ethiopia
}

Copyright (C) 2015 Horizon Research Publishing All rights reserved.

\begin{abstract}
Background: Malaria is the most serious health problem in the world. In order to reduce malaria prevalence, knowing of the level of community awareness towards malaria prevention as well as community practice towards treatment seeking behavior is important. Objective: The aim of the study is to assess and identify the level of community awareness towards malaria, their practice of treatment seeking behavior and its relation to preventive measure. Methods: A community based cross - sectional study was conducted. Data was collected from a sample size of 283 households using structured questionnaires from January $28 / 2013$ to February $8 / 2013$. The questionnaires contain three parts depending on the information they contain. They include information about socio-demography, knowledge of the respondents towards malaria and its prevention and community practice towards malaria and its treatment. Result: A substantial number of respondents responded as they have reasonable knowledge on malaria (90.1\%); including correct association between malaria and mosquito bites $(87.2 \%)$, and most people $(85.8 \%)$ mentioned burning waste material as vector control method and few respondents were bed net owner $(7 \%)$. Nearly greater than half $(55.7 \%)$ of respondents stated that they would seek treatment within $24 \mathrm{hrs}$ of onset of malaria at health facilities as their first treatment option. Finally data was presented in tables, figure and chart. Conclusion: The community overall awareness about the symptoms, cause, transmission and prevention measure of malaria was found to be high. Increasing awareness and access to early malaria diagnosis prompt treatment before the disease become complicated and participation in the health education is vital components in terms of malaria knowledge and practice.
\end{abstract}

Keywords Malaria, Knowledge and Practice

\section{Introduction}

Recent reported that (WHO 2012) malaria is the most important tropical parasitic disease and kills more people than any other communicable disease except tuberculosis. It is political, social, economical and public health problem in more than 98 countries; inhabited by a total of 2.4 million people, i.e. $40 \%$. More than $90 \%$ of all malaria cases are in sub-Saharan Africa. Mortality due to malaria is estimated to be over 863,000 deaths each year. The vast majority of deaths occur in young children in Africa, especially in remote rural areas with poor accesses to health facilities (WHO Malaria report 2009) $(1,3,6)$.

The world malaria situation is deteriorating. During 1940s and early 1950, malaria control activities in Africa were very limited in terms of programs and interventions; except for very specific people such as selected urban settlers of epidemic importance, primarily to students of expatriate population due to failure of eradication strategy due to scarcity of economic resources and faulty adjustment programmers, the lack of effective interaction between project planners and health authorities. The limited participation of African countries in the eradication effort cause a long term negative impact in terms of human resources and capacity building for malaria control in the continent. In Ethiopia even though the Italians had some malaria program in development and settlement areas and some activities were continued by the British and the Ethiopian Government of some major towns in malaria area; there was virtually no control program in the country until the early 1950. A few years later (1970) the eradication, program was dropped and a control program was to be eventually interacted into the general health service $(1,2,3$, 4).

Ethiopia is one of the above stated countries with endemic malaria in Sub-Saharan Africa. Malaria is also among the leading causes of hospitalization and hospital deaths. It is estimated about $2 / 3^{\text {rd }}$ of the country population are at risk of malaria infection. In Ethiopia generally, area below 2000 meters altitude are considered as area of malaria. The people are in the frequent wave of epidemics with predominating plasmodium falciparum followed by plasmodium vivax. To realize the commitment to improve the design of malaria 
control program, ministry of health launched malaria control program and stated preventive strategies $(7,9,11,12,20)$.

Despite the continually intervention efforts which includes drug distribution and intra domestic insecticide spray for the last 30 years; the prevalence of malaria in Ethiopia is very high. Decreasing sensitivity of parasite to chloroquine and decreased susceptibility of vectors to DDT are known to be the major contributing factors. In addition to this the failure of mosquito control program may have resulted from insufficient knowledge of local malaria vector and there ecology and behavior. Such knowledge would permit a better understanding of malaria transmission in order to optimize control strategies aimed at reducing man vector contact $(10,21)$.

The studies conducted in different parts of the world in relation to knowledge, attitude and practice of the community towards malaria reveals that there is a gap between the knowledge and the malaria disease condition which leads them not to participate actively in the control programs $(13,22)$.

As the study conducted to assess the level of knowledge, attitude and practice of the community about malaria and its vector control in South Western Indian (1999) and in Myanmar, Southern Asia showed that a large segment of people were less aware about the danger and transmission of the disease. Even though, study conducted in South Eastern Guatemala (1995) showed that most respondent recognize the role of mosquito in malaria transmission; few of them know the risk of untreated persons $(15,16,18,19)$.

The study conducted in Honde valley, Zimbabwe in 1999, to assess people's perception and knowledge about malaria transmission and control with special reference to the use of plant as mosquito repellent. The result showed that from 226 households, $95 \%$ of the respondents' home had been separated and their understanding of malaria transmission was not related to compliance with the national malaria control programmer. Taking mosquito control measure was related to knowledge of malaria transmission. The use of plants was mentioned by $50(23.5 \%)$ of the respondent and the reason given were that they were cheap $43(86 \%)$, effective (10\%) and locally available $2(4 \%)$. The plant was crushed and applied on the skin by $14.6 \%$, burnt by $72 \%$ and used in their original form by $12.6 \%$ of the people. Finally the result of this study show that, despite wide spread knowledge about the morbidity of malaria, understanding about its prevention was generally low and this has negative implication in the integrated control programs $(14,17)$.

The study conducted in Jimma Town, Ethiopia, on knowledge, attitude and practice of households respondents on malaria etiology showed that most respondents (71.8\%) replied that plasmodium is causative agents and other reported that unhygienic condition(13.1\%) and cold weather(1.4\%) could cause malaria and small number of respondents(13.8\%)did not know the causative agents of malaria, two third of the respondents $(67.4 \%)$ replied that malaria is transmittable disease and $21.3 \%$ did not know whether malaria is transmittable or not; while $(11.3 \%)$ of them believe that malaria is non transmittable disease(23).

Study conducted in Orissa, India, in 2006, on factor affecting treatment seeking behavior for febrile illness in malaria showed that majority of the respondents(281) sought some sort of treatment; examples: government health facilities(35.7\%), less qualified providers(31.3\%) and community level health workers and volunteers(24.3\%). Over the half $(55.7 \%)$ sought treatment from appropriate providers within $48 \mathrm{hrs}$ of onset of symptoms (24).

\section{Method and Materials}

\subsection{The Study Area and Period}

The study was conducted in Jiren kebele. Jiren Kebele is located in Jimma Town; which is located $346 \mathrm{~km}$ South West of Addis Ababa. In Ethiopia, generally, areas below 2000 meters altitude are considered as malaria's area; such as Jimma Town. The study was carried out from January, 28/1/2013 to February, 8/2/2013 at Jiren Kebele.

\subsection{Study Design}

Community based cross- sectional study was conducted in Jiren Kebele; to assess the level of community awareness towards malaria and its treatment among households using structured questionnaire.

\subsection{Study Populations and Sampling Method}

The total number of population living in Jiren Kebele was 6815 with 1083 households. From the population, sample populations are selected by systematic sampling method. The sample size was determined by using the following formula;

$$
\begin{gathered}
\mathrm{n}=\frac{\left(\mathrm{Z}_{\mathrm{s} / 2)^{2} \mathrm{x} p(1-\mathrm{p})}\right.}{\mathrm{d}^{2}} \\
\mathrm{n}=\frac{Z^{2} \mathrm{pq}}{\mathrm{D}^{2}} 1.96^{2} \frac{(0.5)(0.5)}{0.05^{2}}=384
\end{gathered}
$$

Because of population size is less than 10,000; sample size correction is needed.

$$
\begin{gathered}
\mathrm{n}_{\text {final }}=\frac{\mathrm{n}}{1+\frac{\mathrm{n}}{\mathrm{N}}} \\
\mathrm{n}_{\text {final }}=\frac{384}{1+\frac{384}{1083}} \\
\mathrm{n}_{\text {final }}=283
\end{gathered}
$$

- $\mathrm{n}=$ Sample size

- $\mathrm{Z}_{\alpha / 2}=$ the standard normal deviation $=1.96$

- $\mathrm{P}=$ estimated proportion of population $(0.5)$

- $\mathrm{q}=1-\mathrm{p}=0.5$

- $\quad \mathrm{d}=$ precision degree $=0.05$

- $\mathrm{N}=$ Total households (1083)

\subsection{Data Collection Method}


The questionnaire was developed based on the study objective and will be designed as simple as possible to meet the knowledge of both respondent and interviewers to collect the necessary data.

The data collectors are trained for two days on data collection procedure and quality. Systematic random sampling technique was used to select 283 households. Every fifth house $(\mathrm{k}=1083 / 283 \approx 3)$ was selected and one member of the house hold family (the husband, wife or adult of $>18$ ) in every $\mathrm{k}^{\text {th }}$ house was interviewed. The first house was selected using lottery method from first up to $\mathrm{k}^{\text {th }}$ house; starting from the entrance to the kebele.

\subsection{Limitation of the Study}

- This study was carried out in the Jiren Kebele which is not good representative of the rural community

- $\quad$ Failure to use qualitative method

\subsection{Data Processing and Analysis}

The association of the respondents' educational status to their knowledge towards malaria had been analyzed. Finally data was presented in tables, figure and chart using frequency distribution and percentages.

\subsection{Quality Control Methods}

- The pre-test was done to check the feasibility of the study.

- Data collectors had brief orientation on the study and its objective and supervised
- Data was checked for completeness.

\subsection{Ethical Consideration}

Permission letter was written to the authorized body in order to obtain the desired cooperation and participation of the community. The study subjects were requested for their consents to provide the required information. Verbal consent from participants was taken before the interview. Respondents were assured about confidentiality of the information.

\subsection{Study Variables}

Dependent

Knowledge and Practice of the respondents.

Independent

- Educational level

- Age

- Sex

- Ethnicity

- Religion

- Marital status

\section{Results}

A total of 283 households representative $(71.38 \%$ males and $28.62 \%$ females) were interviewed (Table 1 ).

Table 1. Distribution of socio-demographic characteristics of respondents in Jiren Kebele, Jimma Town, January 28-February 8, 2013

\begin{tabular}{|c|c|c|c|}
\hline Sex & Frequency (\%) & Religion & Frequency (\%) \\
\hline Male & $202(71.38)$ & Muslim & $226(79.87)$ \\
\hline Female & $81(28.62)$ & Orthodox & $40(14.13)$ \\
\hline Total & 283 & protestant & $17(6)$ \\
\hline \multicolumn{2}{|l|}{ Age in years } & Total & $283(100)$ \\
\hline $18-29$ & $22(7.77)$ & \multicolumn{2}{|l|}{ Ethnicity } \\
\hline $30-39$ & $54(19.08)$ & Oromo & $251(88.7)$ \\
\hline $40-49$ & $81(28.63)$ & Amhara & $15(5.3)$ \\
\hline $50-59$ & $63(22.26)$ & Gurage & $10(3.53)$ \\
\hline$>60$ & $63(22.26)$ & Dawuro & $7(2.47)$ \\
\hline Total & $283(100)$ & Total & 283 \\
\hline \multicolumn{2}{|l|}{ Marital Status } & \multicolumn{2}{|l|}{ Literacy status } \\
\hline Married & $233(82.33)$ & Illiterate & $77(27.2$ \\
\hline Single & $27(9.54)$ & Grade 18 & $80(28.26$ \\
\hline Widowed & $12(4.24)$ & Grade $9-12$ & $83(29.33$ \\
\hline Divorced & $11(3.89)$ & $>12$ grade & $43(15.21$ \\
\hline Total & 283 & Total & 283 \\
\hline \multicolumn{2}{|c|}{ Family income (in Birr/month) } & \multicolumn{2}{|l|}{ Occupation } \\
\hline$<500$ & $50(17.62)$ & Farmer & $73(25.81)$ \\
\hline $500-1000$ & $105(37.1)$ & Merchant & $59(20.84)$ \\
\hline $1000-1500$ & $38(13.4)$ & Daily laborer & $53(18.72)$ \\
\hline $1500-2000$ & $85(30)$ & House wife & $38(13.43)$ \\
\hline$>2000$ and above & $5(1.73)$ & Employed & $32(11.3)$ \\
\hline Total & 283 & \multirow[t]{5}{*}{ Unemployed } & \multirow[t]{5}{*}{$30(9.89)$} \\
\hline \multicolumn{2}{|c|}{ Number of households members } & & \\
\hline Male & $1013(51.34$ & & \\
\hline Female & $959(48.63$ & & \\
\hline Total & 1972 & & \\
\hline
\end{tabular}


About $(90.1 \%)$ of the respondent had heard and know some information about malaria and responded well (Pie $\underline{\text { chart 1). }}$

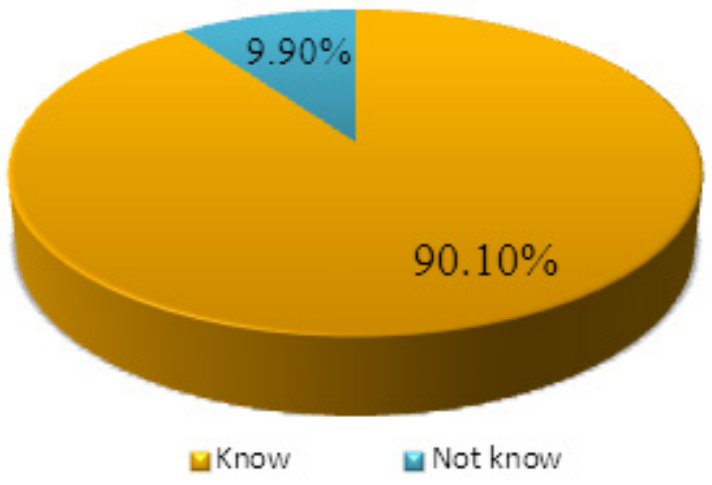

Pie chart 1. Knowledge of the respondents about malaria in Jiren Kebele, Jimma Town, January28-February 8, 2013

Symptoms of malaria such as intermittent fever and headache are frequently mentioned by the respondents when they were asked about the symptoms; $93.72 \%$ and $84.31 \%$ respectively (Table 2 ).

Table 2. Knowledge of malaria symptoms of the study population in Jiren Kebele, Jimma Town, January 28-February 8, 2013

\begin{tabular}{|c|c|}
\hline Symptoms & $\begin{array}{c}\text { No of respondents who } \\
\text { mentioned }\end{array}$ \\
\hline Fever & $239(93.72)$ \\
\hline Headache & $215(84.31)$ \\
\hline Coldness /shivery & $198(77.6)$ \\
\hline Nausea /vomiting & $96(37.64)$ \\
\hline Anorexia & $91(35.68)$ \\
\hline Joint pain & $22(8.6)$ \\
\hline Don't know & $16(6.27)$ \\
\hline
\end{tabular}

Almost all respondents tried to mention the cause of malaria. Most of them (87\%) associated malaria with mosquitobite (Table 3).

Table 3. Knowledge and perception of households towards the causes of malaria in Relation to their educational status, in Jiren Kebele, Jimma Town, January28-February 8, 2013

\begin{tabular}{|c|c|c|c|c|}
\hline \multirow{2}{*}{$\begin{array}{c}\text { S. } \\
\text { No }\end{array}$} & Causes & \multicolumn{3}{|c|}{ № of Respondents } \\
\cline { 3 - 5 } 2 & Male & Female & Total \\
\hline 1 & Mosquito bite & 136 & 86 & 222 \\
\hline 2 & $\begin{array}{c}\text { Drinking } \\
\text { contaminated } \\
\text { water with } \\
\text { mosquito eggs }\end{array}$ & 3 & 6 & 9 \\
\hline 3 & $\begin{array}{c}\text { Eating } \\
\text { contaminated food }\end{array}$ & 1 & 3 & 4 \\
\hline 4 & $\begin{array}{c}\text { Eating ripen fruits } \\
\text { papaya, banana }\end{array}$ & 5 & 9 & 14 \\
\hline 5 & Don't know & 4 & 2 & 6 \\
\hline & Total & $149(60.8 \%)$ & $106(39.2 \%)$ & 245 \\
\hline
\end{tabular}

About $87.45 \%$ of respondents mentioned that malaria could be transmitted from person to person; while $12.55 \%$ of them said malaria cannot transmit from person to person. Most of the population knows that malaria can transmit by mosquito bite (table 4).

Table 4. Knowledge of households/study population on the ways of malarial transmission in Jiren Kebele, Jimma Town, January 28-February 8, 2013

\begin{tabular}{|c|c|c|c|}
\hline $\begin{array}{c}\text { Ways of malaria } \\
\text { transmission }\end{array}$ & Male & Female & Total \\
\cline { 2 - 4 } & $\mathrm{N} \underline{\underline{o}}(\%)$ & $\mathrm{N} \underline{\underline{o}}(\%)$ & $\mathrm{N} \underline{\underline{o}}(\%)$ \\
\hline Mosquito bite & $138(64.78)$ & $85(35.22)$ & $213(95.5)$ \\
\hline $\begin{array}{c}\text { Blood } \\
\text { transfusion }\end{array}$ & 1 & 3 & 4 \\
\hline $\begin{array}{c}\text { By drinking } \\
\text { water }\end{array}$ & 2 & 4 & 6 \\
\hline Total & $141(63.22)$ & $92(36.78)$ & $223(100)$ \\
\hline
\end{tabular}

Relatively, adults are the most part of population who got malaria in the kebele (table 5).

Table 5. Number of family member got sick from malaria since last 3 month in relation to age distribution in Jiren Kebele, Jimma Town, January 28-February 8,2013

\begin{tabular}{|c|c|c|c|}
\hline \multirow{2}{*}{ Age distribution } & \multicolumn{3}{|c|}{ Number of Persons got sick } \\
\hline & Male & Female & Total \\
\hline & $\mathrm{N} \underline{o}(\%)$ & $\mathrm{N} \underline{o}(\%)$ & № $(\%)$ \\
\hline $0-11$ month & 3 & 1 & 4 \\
\hline $12-59$ month & 8 & 6 & 14() \\
\hline 5-14 year & $15(57.7)$ & $11(42.2)$ & $26(29.5)$ \\
\hline 15-64 year & $24(61.53)$ & $15(39.87)$ & $39(44.4)$ \\
\hline $65+$ & 2 & 3 & 5 \\
\hline Total & $52(59.1)$ & $36(39.9)$ & $88(100)$ \\
\hline
\end{tabular}

About $231(90.58 \%)$ respondents believed that malaria is preventable. They mentioned different methods of preventing malaria transmission. Such as; burning wastes $(88.2 \%)$ and the regular use of bed net $(85.49 \%)$ was mentioned frequently (table 6).

Table 6. Malarial control measures perceived by the study population in Jiren Kebele, Jimma Town, January 28-February 8, 2013

\begin{tabular}{|c|c|c|c|}
\hline \multirow{2}{*}{ Control measures } & \multicolumn{3}{|c|}{ Number of Respondents } \\
\cline { 2 - 4 } & Male & Female & Total \\
\cline { 2 - 4 } & $\mathrm{N} \underline{\underline{o}}(\%)$ & $\mathrm{N} \underline{\underline{o}}(\%)$ & $\mathrm{N} \underline{\underline{o}}(\%)$ \\
\hline $\begin{array}{c}\text { Elimination of } \\
\text { breeding site }\end{array}$ & $88(55.7)$ & $70(44.3)$ & $158(67.8)$ \\
\hline DDT-Spray & $28(58.3)$ & $20(41.7)$ & $48(20.6)$ \\
\hline Bed Nets & $123(56.4)$ & $95(43.6)$ & $218(93.5)$ \\
\hline $\begin{array}{c}\text { Early Diagnosis } \\
\text { and treatment }\end{array}$ & $62(56.3)$ & $48(43.7)$ & $110(47.2)$ \\
\hline Burning wastes & $119(52.8)$ & $106(47.2)$ & $225(96.5)$ \\
\hline Total & $489(64.4)$ & $270(35.6)$ & 759 \\
\hline
\end{tabular}

Of total respondents, most of them practice burning wastes and elimination of breeding site. A small number of respondents use bed nets as preventive measures (bar graph $1)$. 


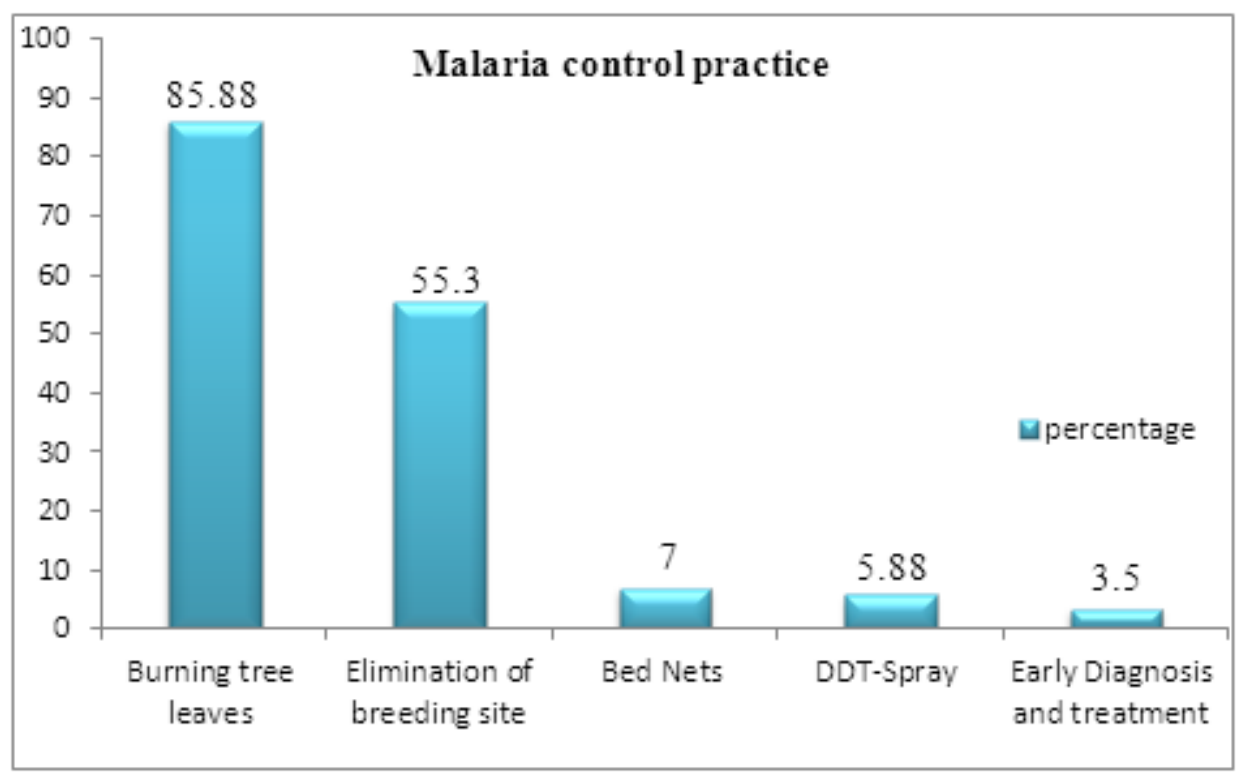

Bar graph 1. Malarial control measures practiced by the respondents in Jiren Kebele, Jimma Town, January28-February 8, 2013

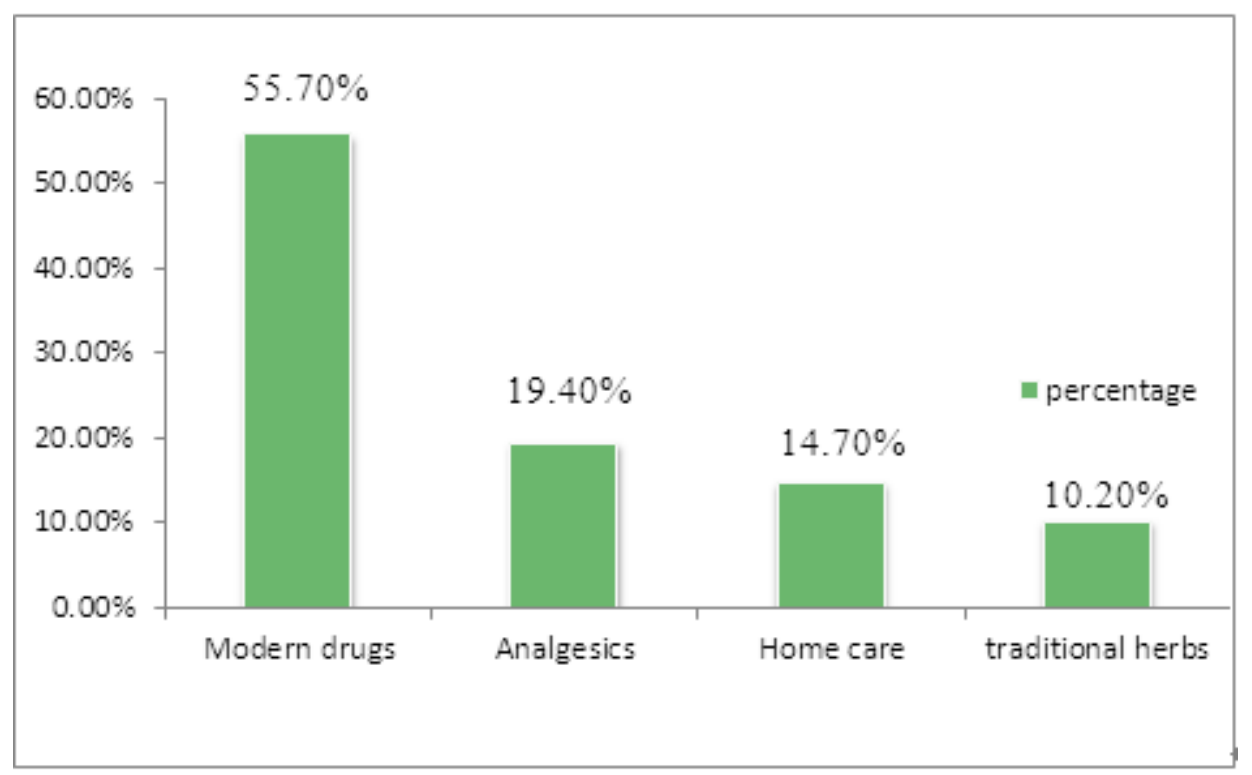

Bar graph 2. Nature of care given for patients with symptoms of malaria in Jiren Kebele, Jimma Town, January28-February 8, 2013

Most people (48.86\%) perceived public health institution as first choice of treatment of malaria; around $(6.8 \%)$ consult private health institution (table 7).

Table 7. Practice of community on treatment seeking behavior to treat malaria in Jiren Kebele, Jimma Town, January28-February 8, 2013

\begin{tabular}{|c|c|}
\hline \multirow{2}{*}{ Actions taken } & Number of respondents \\
\cline { 2 - 2 } & $\mathrm{N} \underline{\underline{o}}(\%)$ \\
\hline Consult Public HI & $43(48.86)$ \\
\hline Self medication & $15(17.1)$ \\
\hline Delay for treatment & $11(12.5)$ \\
\hline Do nothing & 9 \\
\hline Consult private HI & 6 \\
\hline Consult traditional healer & 4 \\
\hline total & $88(100)$ \\
\hline
\end{tabular}

Around $55.7 \%$ of respondents were using modern drugs (antimalarial drugs) for their illness; some of the respondents used traditional medicine (bar graph 2).
Most of the respondents stated reason for delayed treatment is due to self-improvement of the illness; and nearly small number $(10 \%)$ of the respondents claim location of the health institution far away from their home (table 8).

Table 8. Reasons for delaying in treatment seeking behavior by respondents to the symptoms of malaria in Jiren Kebele, Jimma Town, January28-February 8, 2013

\begin{tabular}{|c|c|}
\hline Reason for delayed treatment & Frequency \\
\hline Illness was not serious & 9 \\
\hline No money & 5 \\
\hline Home care is better & 4 \\
\hline Far from home & 2 \\
\hline Total & 20 \\
\hline
\end{tabular}

After the respondents take the medication from the health 
institution; they may/may not take the medication as ordered by health professional (table 9).

Table 9. Ways of taking modern drug (antimalarial drug) by respondents to the symptoms of malaria in Jiren Kebele, Jimma Town, January28-February 8,2013

\begin{tabular}{|c|c|}
\hline Ways drug is taken & $\begin{array}{c}\text { Frequency of respondents who } \\
\text { do it }\end{array}$ \\
\hline Drug used completely & $37(75.5)$ \\
\hline Stopped after relief of symptoms & $10(20.5)$ \\
\hline Shared with family members & 2 \\
\hline Total & 49 \\
\hline
\end{tabular}

\section{Discussion}

This study revealed most of the study population has a good knowledge about the cause of malaria according to the report of the respondents. The majority of the respondents associated the cause of malaria with mosquito bites (87\%) and more than $(12 \%)$ of the respondents mentioned lack of food hygiene, drinking contaminated water with mosquito, eating maize, papaya, and banana and cold weather. It is in contrast to the study conducted in South Western Indian which shows only $27 \%$ of malaria patient knows the correct cause of malaria; a large segment of people was less aware about danger of the disease, about three fourth $(75 \%)$ of the study population did not quit comprehend the purpose of the 5 Decade National Malaria Program (15). This difference may be due to malaria prevalence difference.

Although the belief of community knowledge related with cold weather, drinking contaminated water and eating banana considered as incorrect; the idea may stem from the occurrence of other factor with stated condition which could be a risk factor for malaria. For examples; cold and cloudy weather could be related to the presence of mosquito breeding site. In addition, maize pollen is released following rainy season which can be used as a food source for larval stage enhancing their development. The perception of the study participant could be corrected with appropriate health education which could change their behavior $(23,25)$.

This study has revealed a relative good knowledge about malaria symptoms by this urban population; such that most of the respondents recognize at least one classic symptoms of malaria like intermittent fever commonly. Similar result was found in a similar study in Northern Ethiopia (25).

This study also revealed around $87.45 \%$ respondent mentioned malaria is transmittable disease which is slightly similar result with study conducted in Jimma Town (67.4\%) (23). The role of mosquito in transmission was recognized by 95.5\% of respondents which was higher than from other study conducted in Myanmar, Southern Asia; in which $40 \%$ of people do not have clear cut knowledge on malaria transmission $(16,19)$. The reason for the difference may be malaria prevalence difference and population awareness given by health professional about malaria.
Other study in South Eastern Guatemala shows similar result in which most respondent recognize role of mosquito in malaria transmission (18). Thus understanding of malaria transmission was related with compliance with National Malaria Control Program.

About $90.58 \%$ respondents believed that malaria is preventable disease which is somewhat less than study conducted in Shewa Robit, Ethiopia which shows almost all respondents believe that malaria is preventable (25).

Around $85.8 \%$ of respondents perceive burning waste as preventive measure which is contrast to study conducted in Hondey Valley, Zimbabwe which shows use of plants as mosquito repellents $(14,17)$.

Practices on malaria prevention also reveal that around 225 were practicing burning wastes. This can be one of the reasons for low malaria prevalence detected among the present study participants; however, very low, 7\%, of respondents owned bed net, in contrast to $73 \%$ of respondents in study conducted in South Eastern Guatemala (18). So, not using of bed nets at home during sleeping was a risk factor for malaria transmission in the study kebele. Thus, this study shows community mobilization for creating awareness on appropriate utilization of bed nets is required; as study done in Jimma Town, Ethiopia (23).

Over the half of the respondents $(55.7 \%)$ stated health facilities (both government and private clinic) as their first treatment option. This is consistent with other study in other African countries (62\%) and greater than study conducted in Orissa, India $(35.7 \%)(23,25)$. But, some of the respondents claimed to use traditional medicine $(10.2 \%)$. This shows some variation in health seeking behavior regarding malaria treatment.

A significant proportion of the study participant (12.5\%) would not get treatment within $24 \mathrm{hrs}$ of onset of malaria symptoms; most of which stated waiting for self-improvement due to illness is not severe as a reason $(45 \%)$. This is consistent with the study conducted in other part of the world (24) which is nearly the same $(13 \%)$ that would not get within $24 \mathrm{hrs}$ of onset, and nearly $42.4 \%$ of the respondent in the study conducted in Shewa Robit, Ethiopia stated that they delay for more than 2 or more days (25). So, effective malaria control program should address reducing delayed presentation of patient for treatment.

\section{Conclusions}

In conclusion it is evident that the community overall awareness about the symptoms, cause, transmission and prevention measure of malaria was found to be high. However, knowledge gaps about cause and transmission of malaria were also observed. Burning wastes was the most common malaria preventive method; however, not using bed nets at home during sleeping were seen in the kebele. A significant proportion of the study participant would not get treatment within $24 \mathrm{hrs}$ of onset of malaria symptoms most of them stated awaiting of self-improvement as a reason. 


\section{Acknowledgements}

We want to acknowledge Jimma University Community Based Education office for giving any support required for doing this research.

We would also like to express our appreciation to Jiren Kebele population for their voluntarism to respond to our question and this kebele administrator for their kind cooperation during data collection.

\section{REFERENCES}

[1] E.P $>$ H Expert group report problems; policy and planning in malaria Eth.\% Health Dev. Vol 2 special issue, 1998.

[2] WHO. (1979) WHO expert committee on malaria, Technical report series no 640.71 WHO Geneva.

[3] A. Teklehaimanot, A. Busman: Opportunities, problems and perspectives for malaria control in Sub-Saharan Africa, parasitological 41:335-338, 1999.

[4] Kitaw Y: letter to the editor world health forum. 1981;2(3):433

[5] Glsh, O Malaria Eradication and the selected approach to health care some lesson from Ethiopia INT. Journal of health service 1992:22(1); PP 179-292.

[6] J.Masala Racowbuto, G.Gentile, the commitment for the straggle against malaria in Africa parasitologia Vol 41:361-66.199

[7] MOH: Diagnosis and treatment Guide line for health workers in Ethiopia Addis Ababa July 1996.

[8] Nicto. Tm'End of; carras quill G. knowledge belief and practice relevant to malaria control in urban areas: Soc, Sci, med. Vol 49 (5) 601-601-609, 1999.

[9] MOVBDCP. Natiola program. For malaria and toer vector born discuses 1994; 22 A.A

[10] A. Adugha. B. Petros.M. Wodegiorgis.D. Teelaun M.Mulu. A study of the status of transmission or malaria in sille, south Ethiopian ETH. S.Hel.Dev. 1999:75:80

[11] $\mathrm{MOH}-$ planning and programming department: health and Health indicator 1991 E.C

[12] P.E.C Mensan bohr:FIC,APTO, mensans, tropical discuss $18^{\text {th }}$ edition, 1982
[13] D.S, Turmo G.K.L JN. Ming as and I.C B 4965109. Mother per caption and knowledge on child hood malaria Trop, Med. Int health Vol 5 No 3 pp. 179-184. 2002 Trop, Med.Int.Health Vol 5 NO 3 pp.179-184-2000.

[14] LUKWA N,Ny azema N.Z Cr/units CF; Mwako GL< Shandiw and. Sk. People's perception about malarial and control African 5, Med 45 (3) 199.

[15] Yadv S.P Tyagi B.K; Rammat T. Knowledge and practice malarial in rural community. J. Commune. Dis 31 (2):127-36; 199 Jun-ISSN:0019-5138 midline abstract.

[16] Hia,. Shen; Than Jun. Seein; soe-soe; Tine, aung; Newin; Khinswo-aye: The level of knwlgem, Attitude and practice in relation to malarial; Southern Asian J. Trop, Med pub, health 29 (3) PP. 546-549, 1998. Midline abstract:

[17] Munguti, KJ, Community perception of treatment seeking in malarial EST AFR Med J. Vol, 75 12; PP. 687-91 1998. Midline abstract.

[18] Bovert EJ Klein suan C weller podolfo Zeissing kbp in retain to malaria transmission and vector control A.M.J Trop. Hyg. 52 (5) 1995 PP. 383-88

[19] Govere, J. Durrheim, D: Grange K.La Mabuza A. Booman M. Community knowledge and perception about malaria and practice influencing malaria control. Southern Asian Med. Jou, Vol.90, No 6 2000. PP 611-16 Midline abstract.

[20] MOH Guide line for malaria epidemic prevention and control in Ethiopia, July 1999 P1-6)

[21] Yeneneh. H GYORKOS TW; Joseph, L, Pickering J, Tedela S. Antimalarial drug utilization by women in Ethiopian; knowledge, attitude practice study. Bulthein of WHOL Vol 71 No 6 PP. 763-772, 1993, midline abstract.

[22] Hodes, RM; Teferedegn B. Traditional beliefs and disease practices of Ethiopian Jews Israel J. Med. Sce Vol. 32 No 7 PP. 561. 67, 1996, midline abstract.

[23] A.alemu,W.tsegaye,L.golassa,G.abeba(june 2011) urban malaria and associated risk factors ,malaria journal 2011,10;173, biomedcentral/publisher full text.

[24] Ashis das,TK sundarri Ravindram .factors affecting treatment seeking behavior for febrile malaria illness in malaria, malaria journal 2010,9:377, biomedcenral/publisher full text

[25] A. abate, A.dagerage, B.irko. community knowledge ,attitude and practice about malaria in a low endemic setting of shewa robit town ,northern Ethiopia ,BMC public health $2013,13: 312$ 